\title{
Online emergency department ratings, patient satisfaction and the age-old issue of communication
}

\author{
Megan L Ranney, ${ }^{1}$ Clayton A Peimer ${ }^{2}$
}

${ }^{1}$ Emergency Digital Health Innovation Program, Department of Emergency Medicine, Rhode Island Hospital, Alpert Medical School, Brown University, Providence, Rhode Island, USA ${ }^{2}$ Department of Surgery (Orthopaedics), College of Human Medicine, Michigan State University, Upper Peninsula Health System, Marquette, Michigan, USA

\section{Correspondence to} Dr Megan L Ranney, Emergency Digital Health Innovation Program, Department of Emergency Medicine, Rhode Island Hospital, Alpert Medical School, Brown University, 593 Eddy Street, Claverick 2, Providence, RI 02903, USA;

mranney@lifespan.org

Received 7 September 2015 Accepted 5 October 2015 Published Online First 21 October 2015

\section{SLinked}

- http://dx.doi.org/10.1136/ bmjqs-2015-004035

\section{CrossMark}

To cite: Ranney ML, Peimer CA. BMJ Qual Saf 2016;25:1-2.
Kilaru et $a l^{1}$ report a well-designed and well-executed, retrospective, qualitative study, which suggests that one-third of online (Yelp-sourced) patients' hospital reviews address care in emergency departments (EDs). Using strong qualitative methods, the authors describe the themes emerging from Yelp users' freetext ED reviews. Some of these themescommunication with nurses, communication with doctors and pain control-correspond with the categories in the nationally accepted US Hospital Consumer Assessment of Healthcare Providers and Systems (HCAHPS) survey. Other themes-waiting and efficiency, decisions to seek care in the ED and the events following discharge-differ from HCAHPS' domains. These findings are unlikely to surprise those working in an $\mathrm{ED}$, although the report that the majority of comments are positive may be less expected.

This publication makes a useful contribution to the field of patient safety and satisfaction in several ways. First, it may inform future efforts to obtain patients' feedback on their satisfaction with emergency services. As the authors note, the Center for Medicare and Medicaid Services is currently developing an ED-based version of HCAHPS. We hope that some of the ED-specific themes identified in this paper-which, importantly, match the correlates of ED-related satisfaction and outcome identified by other authors ${ }^{2-4}$-will be included in ED-CAHPS. The authors' findings should also encourage physicians and managers to organise their own systems to develop reproducible patient satisfaction ratings (online, on the phone or in written form that can be computerised). ${ }^{5} \mathrm{~A}$ recent study suggests that one-third of hand surgeons are proactively contacting patients and requesting feedback on quality of care. ${ }^{6}$ Such real-time feedback can help providers and future patients. It would be wonderful to see expansion of such hospital and ED-driven patient satisfaction initiatives to substitute both for paid satisfaction surveys and for less-reliable online hospital and physician rating sites.

Second, Kilaru et al's findings could inform emergency providers' and administrators' efforts to directly improve patients' satisfaction. Some of the issues raised by patients' reviews, such as waiting time and billing, may be perceived as outside of the control of the individual ED. Yet, some EDs have shown that these core issues can be productively addressed in ways that improve both patient care and patient satisfaction. For instance, EDs have improved satisfaction by proactively communicating with patients about wait time, ${ }^{7}$ incorporating Lean manufacturing principles, ${ }^{8}$ and working with hospital leadership to reduce boarding. ${ }^{9}$

Third, online review systems may be more accessible to patients than traditional measures of quality and satisfaction. Yelp has recently announced that it will partner with ProPublica to provide Center for Medicare and Medicaid Services (CMS) data in conjunction with users' Yelp ratings. ${ }^{10}$ Yelp reviews may therefore become an increasingly powerful, and potentially more accurate, alternative to traditional patient satisfaction measures. If we, as providers and administrators, are not satisfied with patients using sites such as Yelp to comment on and drive decisions about healthcare, then we should create a better alternative. This paper may therefore serve as a call to action for professional societies, including the American College of Emergency Physicians and American Medical Association, to offer and advocate for standardised, well-designed, ethical reporting systems-or, perhaps better, to work with Yelp to improve its reporting. 
Important caveats exist, of course, regarding the data presented in Kilaru et al's manuscript, and by extension the data gathered by Yelp and other online healthcare review sites. Most importantly, the post hoc assessments presented in this manuscript are spontaneously submitted, not systematically solicited. People are more likely to voluntarily offer comments regarding the very good or very bad. In this study, the majority of Yelp reviews identified by the authors were either 'excellent' or 'poor'. The middle ground may therefore be missed by Yelp in general, and by this study in particular. Medical societies could help address this deficiency by working with Yelp or other proprietary systems to solicit a wider cross-section of opinions.

Similarly, the population represented by Yelp reviews (and, therefore, by this study) may be biased. According to Yelp's own statistics, those who use it are younger and more affluent than the average American. ${ }^{11}$ Although we do not know many demographics of the reviewers in Kilaru et al's manuscript, we suspect that these biases hold true. Small-sized hospitals' EDs were also less likely to be represented in Yelp reviews. A wider cross-section of our patients and families need easy access to technology, and a clear understanding of the value of providing feedback, in order to ensure the accuracy of this reporting system.

Last, Yelp reviews by definition reflect patients' (and families') perceptions rather than actual quality of care provided in the ED. As others have noted, satisfaction correlates only weakly with quality ${ }^{12}$; and many determinants of patients' satisfaction are non-modifiable. ${ }^{13}$ It would be interesting to compare EDs' Yelp reviews both to other measures of patient satisfaction (eg, Press-Ganey) and to objective measures of quality.

Despite these limitations, Kilaru et al's manuscript serves as a call to providers. Their themes emphasise the need for improved communication (between providers, about wait times, about next steps). It proves yet again that we must deliver care well and also ask how well we are doing and communicate that we care.

Twitter Follow Megan Ranney at @meganranney

Contributors Both authors had substantial contributions to the conception or design of the work, drafted the work and revised it critically for important intellectual content, gave final approval of the version to be published and agree to be accountable for all aspects of the work in ensuring that questions related to the accuracy or integrity of any part of the work are appropriately investigated and resolved.

Competing interests None declared.

Provenance and peer review Commissioned; internally peer reviewed.

\section{REFERENCES}

1 Kilaru AS, Meisel ZF, Paciotti B, et al. What do patients say about emergency departments in online reviews? A qualitative study. BMJ Qual Saf 2016;25:14-24.

2 Rising KL, Padrez KA, O’Brien M, et al. Return visits to the emergency department: the patient perspective. Ann Emerg Med 2015;65:377-86.e3.

3 Forsgärde ES, From Attebring M, Elmqvist C. Powerlessness dissatisfied patients' and relatives' experience of their emergency department visit. Int Emerg Nurs 2015. [Epub ahead of print 5 Aug 2015].

4 Taylor C, Benger JR. Patient satisfaction in emergency medicine. Emerg Med J 2004;21:528-32.

5 Strech D. Ethical principles for physician rating sites. J Med Internet Res 2011;13:e113.

6 Samora JB, Lifchez SD, Blazar PE; American Society for Surgery of the Hand Ethics and Professionalism Committee. Physician-Rating Web Sites: Ethical Implications. J Hand Surg Am [epub ahead of print 22 Aug 2015]. doi: 10.1016/j. jhsa.2015.05.034.

7 http:/health.usnews.com/health-news/articles/2012/09/12/ no-wait-at-the-er

8 Kane M, Chui K, Rimicci J, et al. Lean manufacturing improves emergency department throughput and patient satisfaction. J Nurs Adm 2015;45:429-34.

9 Patel PB, Combs MA, Vinson DR. Reduction of admit wait times: the effect of a leadership-based program. Acad Emerg Med 2014;21:266-73.

10 http://officialblog.yelp.com/2015/08/yelps-consumerprotection-initiative-propublica-partnership-brings-medicalinfo-to-yelp.html

11 http://www.yelp.com/advertise/agency/audience

12 Fenton JJ, Jerant AF, Bertakis KD, et al. The cost of satisfaction: a national study of patient satisfaction, health care utilization, expenditures, and mortality. Arch Intern Med 2012;172:405-11.

13 Abtahi AM, Presson AP, Zhang C, et al. Association between orthopaedic outpatient satisfaction and non-modifiable patient factors. J Bone Joint Surg Am 2015;97:1041-8. 